\title{
EFFECT OF HEAT SOURCE AND CHEMICAL REACTION ON MHD FLOW PAST A VERTICAL PLATE WITH VARIABLE TEMPERATURE
}

\author{
P. K. Rout ${ }^{1}$, S. N. Sahoo ${ }^{2}$ and G. C. Dash ${ }^{3}$
}

${ }^{1}$ Department of Mathematics, Gandhi Institute For Technology, Bhubaneswar, Odisha, India, Email: pkrout.72@ rediffmail.com

${ }^{2}$ Department of Mathematics, Institute of Technical Education and Research, Siksha 'O' Anusandhan University, Khandagiri, Bhubaneswar-30, Odisha, India, Email: sachimath1975@gmail.com

${ }^{3}$ Department of Mathematics, Institute of Technical Education and Research, Siksha 'O' Anusandhan University, Khandagiri, Bhubaneswar-30, Odisha, India, Email: gcdash45@gmail.com

\section{Abstract:}

An analysis has been carried out to study the effect of heat source and chemical reaction on MHD flow past a vertical plate subject to a constant motion with variable temperature and concentration. The governing equations are solved by the Laplace transformation technique. The effects of various flow parameters on the flow dynamics are discussed. Findings of the present study reveal that the velocity of the fluid reduces due to the dominating effect of kinematic viscosity over molecular diffusivity in case of heavier species. Presence of heat source reduces the velocity of the flow. Presence of chemical reaction parameter decreases the concentration distribution.

Keywords: MHD, heat source, chemical reaction, variable temperature

\section{NOMENCLATURE}

$\begin{array}{ll}x, y & \text { coordinate axes } \\ y^{*} & \text { dimensional coordinate } \\ u^{*} & \text { dimensional velocity } \\ u & \text { nondimensional velocity } \\ t & \text { time variable } \\ T & \text { dimensional temperature } \\ T_{\mathrm{w}} & \text { temperature at the plate } \\ T_{\infty} & \text { ambient temperature } \\ C^{*} & \text { dimensional concentration } \\ C & \text { nondimensionl concentration } \\ C_{\mathrm{w}} & \text { concentration at the plate } \\ C_{\infty} & \text { ambient concentration } \\ B_{0} & \text { external magnetic field } \\ k & \text { thermal conductivity of the fluid } \\ \mathrm{g} & \text { acceleration due to gravity } \\ \mathrm{D} & \text { mass diffusion coefficient } \\ M & \text { magnetic field parameter }\end{array}$

$$
\begin{array}{ll}
\mathrm{Gm} & \text { mass Grashof number } \\
K & \text { dimensional porosity parameter } \\
P r & \text { Prandtl number } \\
\mathrm{Gr} & \text { thermal Grashof number } \\
\mathrm{Sc} & \text { Schmidt number } \\
K_{\mathrm{p}} & \text { dimensional porosity parameter } \\
C_{p} & \text { specific heat at constant pressure } \\
Q_{0} & \text { dimensional heat source parameter }
\end{array}
$$

\section{Greek symbols}

$\phi \quad$ nondimensional heat source parameter

$\rho \quad$ fluid density

$v \quad$ kinematics viscosity

$\sigma \quad$ Stefan-Boltzmann constant

$\theta \quad$ nondimensional temperature

$\beta \quad$ volumetric coefficient of thermal expansion

$\hat{\beta} \quad$ volumetric coefficient of concentration

$\mu \quad$ coefficient of viscosity 


\section{Introduction}

The study of MHD flow with heat and mass transfer plays an important role in chemical, mechanical and biological sciences. Some important applications are cooling of nuclear reactors, liquid metals fluid, power generation system and aero dynamics. Chamkha (2004) has studied unsteady MHD convective heat and mass transfer past a semi-infinite vertical permeable moving plate with heat absorption. Muthukumarswamy and Janakiraman (2006) have studied radiation effects on MHD flow moving through an isothermal vertical plate with variable mass diffusion. Again, Muthukumarswamy et al. (2008) have analyzed mass transfer effects on exponentially accelerated isothermal vertical plate. Prasad et al. (2007) have discussed radiation and mass transfer effects on two-dimensional flow past an impulsively started infinite vertical plate. Das et al. (2008) analyze the three dimensional coquette flow of a viscous incompressible electrically conducting fluid between two infinite horizontal parallel porous flat plates in presence of a transverse magnetic field. Seth and Ansari (2010) have studied the MHD natural convection flow past an impulsively moving vertical plate with ramped wall temperature in the presence of thermal diffusion with heat absorption. Rajput and Kumar (2011) have analyzed the MHD flow past an impulsively started vertical plate with variable temperature and mass diffusion.

A chemical reaction is said to be of first order if its reaction rate is directly proportional to the concentration itself (1988). The effect of a chemical reaction on a moving isothermal vertical surface with suction has been studied by Muthucumarswamy (2002). Continuing this endeavor on the study of a chemical reaction, Kandasamy et al. (2005) considered the chemical reaction and thermal stratification effects over a vertically stretching surface. A viscous flow over a non-linearly stretching sheet in the presence of chemical reaction and magnetic field has been studied by Raptis et al. (2006). Mahmoud (2007) has discussed the chemical reaction effect on a mixed convection flow of heat and mass transfer along a semi-infinite vertical plate. Al-Qdat and Al-Azab (2007) studied the influence of a chemical reaction on transient MHD free convection flow over a moving vertical plate. Mahapatra et al. (2010) have studied the effects of chemical reaction on free convection flow through a porous medium bounded by a vertical surface. Recently, Kar et al. (2014) have analyzed the heat and mass transfer effects on a dissipative and radiative visco-elastic MHD flow over a stretching porous sheet.

In the present study we have extended the work of Rajput and Kumar (2011) by incorporating heat source and chemical reaction. The analysis of the results obtained reveals that the flow field is influenced by the heat source and chemical reaction parameters. It is hoped that these results will not only provide useful information for application, but also will serve as a complement to the previous study.

\section{Mathematical Formulation}

In our study we have considered the flow of unsteady viscous incompressible and electrically conducting fluid. The $x$ - axis is taken along the plate in the upward direction and $y$-axis is perpendicular to it. A transverse magnetic field $B_{0}$, of uniform strength is applied normal to the plate. The viscous dissipation, Julian dissipation and induced magnetic field have been neglected in the present model. Initially, the fluid and plate are at the same temperature $T_{\infty}$ and concentration $C_{\infty}$ in the stationary condition. At time $\mathrm{t}>0$, temperature of the plate is raised to $T_{\mathrm{w}}$ and the concentration level near the plate is raised linearly with respect to time. Under these assumptions and taking into account the Boussinesq and the boundary layer approximations, the system of momentum, energy and concentration equations are

$$
\begin{aligned}
& \frac{\partial u}{\partial t}=v \frac{\partial^{2} u}{\partial y^{2}}-\frac{\sigma B_{0}^{2} u}{\rho}+g \beta\left(T-T_{\infty}\right)+g \hat{\beta}\left(C-C_{\infty}\right) \\
& \frac{\partial T}{\partial t}=\frac{k}{\rho C_{p}} \frac{\partial^{2} T}{\partial y^{2}}-\frac{Q_{0}}{\rho C_{p}}\left(T-T_{\infty}\right) \\
& \frac{\partial C}{\partial t}=D \frac{\partial^{2} C}{\partial y^{2}}-K_{l}\left(C-C_{\infty}\right)
\end{aligned}
$$

There is no convective acceleration term in the governing equations and hence the present flow model is related to slow motion and is valid for low Reynolds number less than 1 . Therefore, viscosity force dominates over the inertia force. Dropping the convective terms in governing equations definitely reduces the equations linear but that is not the sole objective. Even if non-linear terms are there, the problem can be solved by applying Laplace Transform by quasi linearization technique. The method suggests that in the first iteration the nonlinear terms 
are neglected. The linear equation is solved under Laplace Transform. Then the solution so obtained is to be substituted in the whole equation consisting of the non-linear part. The process is repeated till the sequence of solution attains a fixed value.

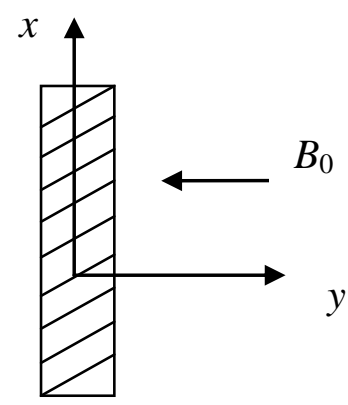

Fig. 1: Flow Geometry

The following boundary conditions have been assumed:

$$
\left.\begin{array}{c}
t \leq 0: u=0, T=T_{\infty}, C=C_{\infty} \text { for all } y \\
t>0: u=u_{0}, T=T_{\infty}+\left(T_{w}-T_{\infty}\right) \frac{u_{0}^{2} t}{v}, C=C_{\infty}+\left(C_{w}-C_{\infty}\right) \frac{u_{0}^{2} t}{v} \text { at } y=0 \\
u \rightarrow 0, T \rightarrow T_{\infty}, C \rightarrow C_{\infty} \text { as } y \rightarrow \infty
\end{array}\right\}
$$

\section{Method of Solution}

Introducing the following non dimensional quantities

$$
\begin{aligned}
& y^{*}=\frac{y u_{0}}{v}, u^{*}=\frac{u}{u_{0}}, t^{*}=\frac{t u_{0}^{2}}{v}, M=\frac{\sigma B_{0}^{2} v}{\rho u_{0}^{2}}, P_{r}=\frac{v \rho C_{p}}{k}, S_{c}=\frac{v}{D}, \theta=\frac{T-T_{\infty}}{T_{w}-T_{\infty}}, C^{*}=\frac{C-C_{\infty}}{C_{w}-C_{\infty}}, \\
& G r=\frac{g \beta v\left(T_{w}-T_{\infty}\right)}{u_{0}^{3}}, G m=\frac{g \hat{\beta} v\left(C_{w}-C_{\infty}\right)}{u_{0}^{3}}, \phi=\frac{v Q_{0}}{\rho C_{p} u_{0}^{2}}, K_{c}=\frac{K_{l} v}{u_{0}{ }^{2}}
\end{aligned}
$$

in Eqns. (1), (2) and (3) and dropping the asterisks, we have

$$
\begin{aligned}
& \frac{\partial u}{\partial t}=\frac{\partial^{2} u}{\partial y^{2}}-M u+G r \theta+G m C \\
& \frac{\partial \theta}{\partial t}=\frac{1}{\operatorname{Pr}} \frac{\partial^{2} \theta}{\partial y^{2}}-\phi \theta \\
& \frac{\partial C}{\partial t}=\frac{1}{S c} \frac{\partial^{2} C}{\partial y^{2}}-K_{c} C
\end{aligned}
$$

The corresponding initial and boundary conditions are

$$
\begin{gathered}
\left.\begin{array}{c}
t \leq 0: u=0, \theta=0, C=0 \text { for all } y=0 \\
t>0: u=1, \theta=t, C=t \text { at } y=0 \\
u \rightarrow 0, \theta \rightarrow 0, C \rightarrow 0 \text { as } y \rightarrow \infty
\end{array}\right\} \\
\frac{\partial^{2} \bar{u}}{\partial y^{2}}-(s+M) \bar{u}=-\frac{G r}{s^{2}} e^{-\sqrt{\operatorname{Pr}(s+\phi) y}}-\frac{G m}{s^{2}} e^{-\sqrt{S c\left(s+K_{c}\right) y}} \\
\frac{\partial^{2} \bar{\theta}}{\partial y^{2}}-\operatorname{Pr}(s+\phi) \bar{\theta}=0
\end{gathered}
$$


$\frac{\partial^{2} \bar{C}}{\partial y^{2}}-S c\left(s+K_{c}\right) \bar{C}=0$

The corresponding boundary conditions are

$t>0:\left\{\begin{array}{l}\bar{u}=1 / s, \bar{\theta}=1 / s^{2}, \bar{C}=1 / s^{2} \quad \text { at } y=0 \\ \bar{u} \rightarrow 0, \bar{\theta} \rightarrow 0, \bar{C} \rightarrow 0 \quad \text { as } y \rightarrow \infty\end{array}\right.$

The solutions of Equations (9), (10) and (11) subject to the boundary conditions (12) are given by

$$
\begin{aligned}
& \theta(y, t)=\frac{1}{2}\left[\left(t+\frac{y}{2} \sqrt{\frac{P r}{\phi}}\right) e^{y \sqrt{P r \phi}} \operatorname{erfc}\left(\frac{y}{2} \sqrt{\frac{P r}{t}}+\sqrt{\phi t}\right)+\left(t-\frac{y}{2} \sqrt{\frac{P r}{\phi}}\right) e^{-y \sqrt{P r \phi}} \operatorname{erfc}\left(\frac{y}{2} \sqrt{\frac{P r}{t}}-\sqrt{\phi t}\right)\right] \text {, } \\
& C(y, t)=\frac{1}{2}\left[\left(t+\frac{y}{2} \sqrt{\frac{S c}{K_{c}}}\right) e^{y \sqrt{S c K_{c}}} \operatorname{erfc}\left(\frac{y}{2} \sqrt{\frac{S c}{t}}+\sqrt{K_{c} t}\right)\right. \\
& \left.+\left(t-\frac{y}{2} \sqrt{\frac{S c}{K_{c}}}\right) e^{-y \sqrt{S c K_{c}}} \operatorname{erfc}\left(\frac{y}{2} \sqrt{\frac{S c}{t}}-\sqrt{K_{c} t}\right)\right], \\
& u(y, t)=\frac{1}{2}\left[e^{y \sqrt{M}} \operatorname{erfc}\left(\frac{y}{2 \sqrt{t}}+\sqrt{M t}\right)+e^{-y \sqrt{M}} \operatorname{erfc}\left(\frac{y}{2 \sqrt{t}}-\sqrt{M t}\right)\right]-\alpha_{1} F(y, t)-\alpha_{2} R(y, t)
\end{aligned}
$$

where

$$
\begin{aligned}
& F(y, t)=\left[\frac{1}{\beta_{1}}\left(t+\frac{1}{\beta_{1}}+\frac{y}{2 \sqrt{M}}\right) e^{y \sqrt{M}} \operatorname{erfc}\left(\frac{y}{2 \sqrt{t}}+\sqrt{M t}\right)+\frac{1}{\beta_{1}}\left(t+\frac{1}{\beta_{1}}-\frac{y}{2 \sqrt{M}}\right) e^{-y \sqrt{M}} \operatorname{erfc}\left(\frac{y}{2 \sqrt{t}}-\sqrt{M t}\right)\right. \\
& -\frac{1}{\beta_{1}}\left(t+\frac{1}{\beta_{1}}+\frac{y}{2} \sqrt{\frac{P r}{\phi}}\right) e^{y \sqrt{\operatorname{Pr\phi }}} \operatorname{erfc}\left(\frac{y}{2} \sqrt{\frac{\operatorname{Pr}}{t}}+\sqrt{\phi t}\right)-\frac{1}{\beta_{1}}\left(t+\frac{1}{\beta_{1}}+\frac{y}{2} \sqrt{\frac{\operatorname{Pr}}{\phi}}\right) e^{-y \sqrt{\operatorname{Pr\phi }}} \operatorname{erfc}\left(\frac{y}{2} \sqrt{\frac{\operatorname{Pr}}{t}}-\sqrt{\phi t}\right) \\
& -\frac{e^{\beta_{1} t}}{\beta_{1}^{2}}\left\{e^{y \sqrt{M+\beta_{1}}} \operatorname{erfc}\left(\frac{y}{2 \sqrt{t}}+\sqrt{\left(M+\beta_{1}\right) t}\right)+e^{-y \sqrt{M+\beta_{1}}} \operatorname{erfc}\left(\frac{y}{2 \sqrt{t}}-\sqrt{\left(M+\beta_{1}\right) t}\right)\right. \\
& \left.\left.-e^{y \sqrt{\operatorname{Pr}\left(\phi+\beta_{1}\right)}} \operatorname{erfc}\left(\frac{y}{2} \sqrt{\frac{\operatorname{Pr}}{t}}+\sqrt{\left(\phi+\beta_{1}\right) t}\right)-e^{-y \sqrt{\operatorname{Pr}\left(\phi+\beta_{1}\right)}} \operatorname{erfc}\left(\frac{y}{2} \sqrt{\frac{\operatorname{Pr}}{t}}-\sqrt{\left(\phi+\beta_{1}\right) t}\right)\right\}\right], \\
& \mathrm{R}(y, t)=\left[\frac{1}{\beta_{2}}\left(t+\frac{1}{\beta_{2}}+\frac{y}{2 \sqrt{M}}\right) e^{y \sqrt{M}} \operatorname{erfc}\left(\frac{y}{2 \sqrt{t}}+\sqrt{M t}\right)+\frac{1}{\beta_{2}}\left(t+\frac{1}{\beta_{2}}-\frac{y}{2 \sqrt{M}}\right) e^{-y \sqrt{M}} \operatorname{erfc}\left(\frac{y}{2 \sqrt{t}}-\sqrt{M t}\right)\right. \\
& -\frac{1}{\beta_{2}}\left(t+\frac{1}{\beta_{2}}+\frac{y}{2} \sqrt{\frac{S c}{K_{c}}}\right) e^{y \sqrt{S c K_{c}}} \operatorname{erfc}\left(\frac{y}{2} \sqrt{\frac{S c}{t}}+\sqrt{K_{c} t}\right)-\frac{1}{\beta_{2}}\left(t+\frac{1}{\beta_{2}}+\frac{y}{2} \sqrt{\frac{S c}{K_{c}}}\right) e^{-y \sqrt{S c K_{c}}} \operatorname{erfc}\left(\frac{y}{2} \sqrt{\frac{S c}{t}}-\sqrt{K_{c} t}\right) \\
& -\frac{e^{\beta_{2} t}}{\beta_{2}^{2}}\left\{e^{y \sqrt{M+\beta_{2}}} \operatorname{erfc}\left(\frac{y}{2 \sqrt{t}}+\sqrt{\left(M+\beta_{2}\right) t}\right)+e^{-y \sqrt{M+\beta_{2}}} \operatorname{erfc}\left(\frac{y}{2 \sqrt{t}}-\sqrt{\left(M+\beta_{2}\right) t}\right)\right. \\
& \left.-e^{y \sqrt{\mathrm{Sc}\left(\mathrm{K}_{c}+\beta_{2}\right)}} \operatorname{erfc}\left(\frac{y}{2} \sqrt{\frac{S c}{t}}+\sqrt{\left(\mathrm{K}_{c}+\beta_{2}\right) t}\right)-e^{-y \sqrt{\operatorname{Sc}\left(\mathrm{K}_{c}+\beta_{2}\right)}} \operatorname{erfc}\left(\frac{y}{2} \sqrt{\frac{S c}{t}}-\sqrt{\left(\mathrm{K}_{c}+\beta_{2}\right) t}\right)\right\},
\end{aligned}
$$




\section{Nusselt number}

The expression for the rate of heat transfer in terms of Nusselt number $(\mathrm{Nu})$ is given by

$$
\left.N u=-\frac{\partial \theta}{\partial y}\right]_{y=0}=\frac{1}{2} \sqrt{\frac{\operatorname{Pr}}{\phi}}\{1-\operatorname{erfc}(\sqrt{\phi t})\}+t \sqrt{\operatorname{Pr} \phi}+t\left\{\sqrt{\frac{\operatorname{Pr}}{\pi t}} e^{-\phi t}-\sqrt{\operatorname{Pr}} \operatorname{erfc}(\sqrt{\phi t})\right\},
$$

\section{Sherwood number}

The expressions for the rate of mass transfer in terms of Sherwood number (Sh) is given by

$$
\left.S h=-\frac{\partial C}{\partial y}\right]_{y=0}=\frac{1}{2} \sqrt{\frac{S c}{K_{c}}}\left\{1-\operatorname{erfc}\left(\sqrt{K_{c} t}\right)\right\}+t \sqrt{K_{c} S c}+t\left\{\sqrt{\frac{S c}{\pi t}} e^{-K_{c} t}-\sqrt{K_{c} S c} \operatorname{erfc}\left(\sqrt{K_{c} t}\right)\right\},
$$

\section{Skin-friction}

The expressions for skin-friction $(\tau)$ which are measures shear stress at the plate is given by

$$
\left.\tau=\frac{\partial u}{\partial y}\right]_{y=0}=\sqrt{M}(\operatorname{erfc}(\sqrt{M t})-1)-\frac{1}{\sqrt{\pi t}} e^{-M t}+\alpha_{1} F_{2}(y, t)-\alpha_{2} R_{2}(y, t),
$$

where

$$
\begin{aligned}
& F_{2}(y, t)=\frac{1}{2 \beta_{1} \sqrt{M}}(1-\operatorname{erfc}(\sqrt{M t}))+\frac{1}{\beta_{1}}\left(t+\frac{1}{\beta_{1}}\right)\left\{\sqrt{M}(1-\operatorname{erfc}(\sqrt{M t}))+\frac{1}{\sqrt{\pi t}} e^{-M t}\right\} \\
& -\frac{1}{\beta_{1}}\left[\left(t+\frac{1}{\beta_{1}}\right) \sqrt{\operatorname{Pr} \phi}(1-\operatorname{erfc} \sqrt{\phi t})+\frac{1}{2}\left(t+\frac{1}{\beta_{1}}\right) \sqrt{\frac{\operatorname{Pr}}{\pi t}}(2-\operatorname{erfc} \sqrt{\phi t})-\frac{1}{2} \sqrt{\frac{\operatorname{Pr}}{\phi}}+\left(t+\frac{1}{\beta_{1}}\right) \sqrt{\left.\frac{\operatorname{Pr}}{\pi t} e^{-\phi t}\right]}\right. \\
& +\left(1 / \beta_{1}^{2}\right) e^{\beta_{1} t}\left[\sqrt{M+\beta_{1}}\left(\operatorname{erfc}\left(\sqrt{\left(M+\beta_{1}\right) t}-1\right)\right)-\frac{1}{\sqrt{\pi t}} e^{-\left(M+\beta_{1}\right) t}\right. \\
& \left.\quad+\sqrt{\operatorname{Pr}\left(\phi+\beta_{1}\right)}\left(1-\operatorname{erfc}\left(\sqrt{\left(\phi+\beta_{1}\right) t}\right)\right)+\frac{\operatorname{Pr}}{\sqrt{\pi t}} e^{-\left(\phi+\beta_{1}\right) t}\right], \\
& R_{2}(y, t)=\frac{1}{2 \beta_{2} \sqrt{M}}(1-\operatorname{erfc}(\sqrt{M t}))+\frac{1}{\beta_{2}}\left(t+\frac{1}{\beta_{2}}\right)\left\{\sqrt{M}(1-\operatorname{erfc}(\sqrt{M t}))+\frac{1}{\sqrt{\pi t}} e^{-M t}\right\} \\
& -\frac{1}{\beta_{2}}\left[\left(t+\frac{1}{\beta_{2}}\right) \sqrt{S c K_{c}}\left(1-\operatorname{erfc} \sqrt{K_{c} t}\right)+\frac{1}{2}\left(t+\frac{1}{\beta_{2}}\right) \sqrt{\frac{S c}{\pi t}}\left(2-\operatorname{erfc} \sqrt{K_{c} t}\right)-\frac{1}{2} \sqrt{\frac{S c}{K_{c}}}+\left(t+\frac{1}{\beta_{2}}\right) \sqrt{\frac{S c}{\pi t}} e^{-K_{c} t}\right] \\
& +\left(1 / \beta_{2}{ }^{2}\right) e^{\beta_{2} t}\left[\sqrt{M+\beta_{2}}\left(\operatorname{erfc}\left(\sqrt{\left(M+\beta_{2}\right) t}-1\right)\right)-\frac{1}{\sqrt{\pi t}} e^{-\left(M+\beta_{2}\right) t}\right. \\
& \left.\quad+\sqrt{\operatorname{Sc}\left(K_{c}+\beta_{2}\right)}\left(1-\operatorname{erfc}\left(\sqrt{\left(K_{c}+\beta_{2}\right) t}\right)\right)+\frac{S c}{\sqrt{\pi t}} e^{-\left(K_{c}+\beta_{2}\right) t}\right]
\end{aligned}
$$

$\alpha_{1}, \beta_{1}, \alpha_{2}$ and $\beta_{2}$ are defined as:

$$
\alpha_{1}=\frac{G r}{\operatorname{Pr}-1}, \beta_{1}=\frac{\operatorname{Pr} \phi-M}{1-\operatorname{Pr}}, \alpha_{2}=\frac{G c}{S c-1}, \beta_{2}=\frac{S c K_{c}-M}{1-S c}
$$




\section{Results and Discussion}

Discussion has been carried out to study the effect of heat source and chemical reaction on MHD flow past a vertical plate subject to a constant motion with variable temperature and concentration.

\subsection{Effect of flow parameters on velocity profile}

In order to get a physical insight into the problem, a representative set of results is shown graphically. Effects of the pertinent parameters are discussed below analyzing the graphs and tables.

\subsubsection{Effect of Prandtl number on velocity profile}

Fig. 2 shows the effect of Prandtl number $(\operatorname{Pr})$ on velocity profile. In this figure we have taken $M=0.5$, $\mathrm{Gr}=\mathrm{Gm}=2, \mathrm{Sc}=2, K_{\mathrm{c}}=\phi=\mathrm{t}=1$. As Pr increases, the velocity of the fluid decreases in the entire flow domain. Prandtl number is ratio of the kinematic viscosity to the thermal diffusivity of the fluid and it measures the relative importance of heat conduction and viscosity of the fluid. For less viscous fluids $(\operatorname{Pr}<1)$, the kinematic viscosity is dominated by the thermal diffusivity of the fluid. For highly viscous fluids $(\operatorname{Pr}>1)$, the kinematic viscosity dominates the thermal diffusivity of the fluid. As a result of which a multilayer character exhibits in the fluid flow.

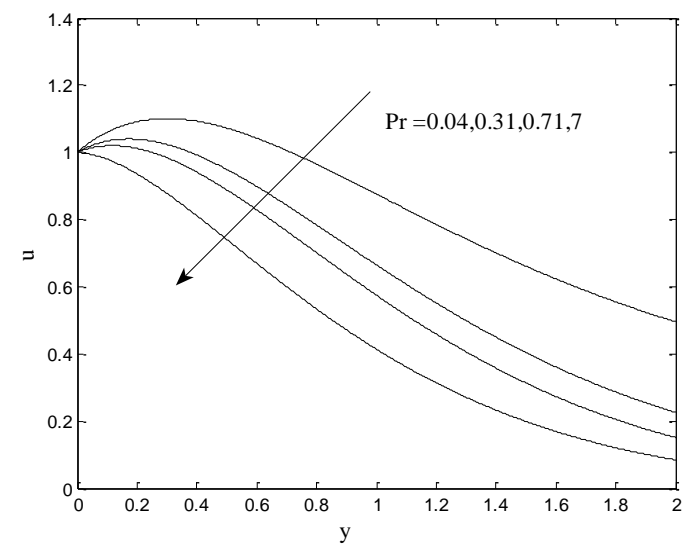

Fig. 2: Effect of Pr on velocity profile

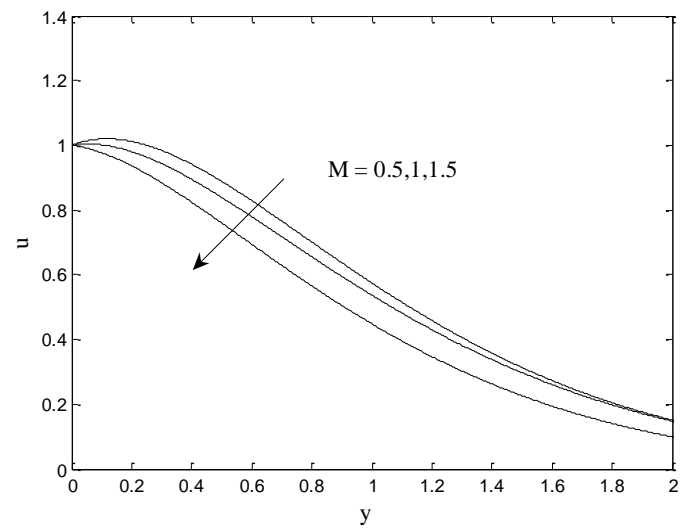

Fig. 3: Effect of $\mathrm{M}$ on velocity profile

\subsubsection{Effect of magnetic parameter on velocity profile}

Fig. 3 depicts the effect of magnetic parameter (M) on velocity profile. In this figure we have taken $\operatorname{Pr}=0.71$, $\mathrm{Gr}=\mathrm{Gm}=2, \mathrm{Sc}=2, K_{\mathrm{c}}=\phi=\mathrm{t}=1$. As $\mathrm{M}$ increases the velocity of the fluid decreases, which shows that the magnetic parameter has a retarding effect on the velocity field.

\subsubsection{Effect of thermal Grashof number on velocity profile}

Fig. 4 shows the effect of thermal Grashof number $(\mathrm{Gr})$ on velocity profile. In this figure we have taken $\operatorname{Pr}=0.71, \mathrm{M}=0.5, \mathrm{Gm}=2, \mathrm{Sc}=2, K_{\mathrm{c}}=\phi=\mathrm{t}=1$. Thermal Grashof number characterizes the free convection of the flow. The velocity of the fluid increases with the increase in Gr. Hence, the thermal Grashof number has an accelerating effect on the velocity profile.

\subsubsection{Effect of mass Grashof number on velocity profile}


Figs.5 shows the effect of mass Grashof number $(\mathrm{Gm})$ on velocity profile. In this figure we have taken $\operatorname{Pr}=0.71, \mathrm{M}=0.5, \mathrm{Gr}=2, \mathrm{Sc}=2, K_{\mathrm{c}}=\phi=\mathrm{t}=1$. It is observed that buoyancy effect due to solutal concentration enhances the velocity of the fluid within the range $0 \leq y \leq 1.3$, and then the reverse effect occurs.

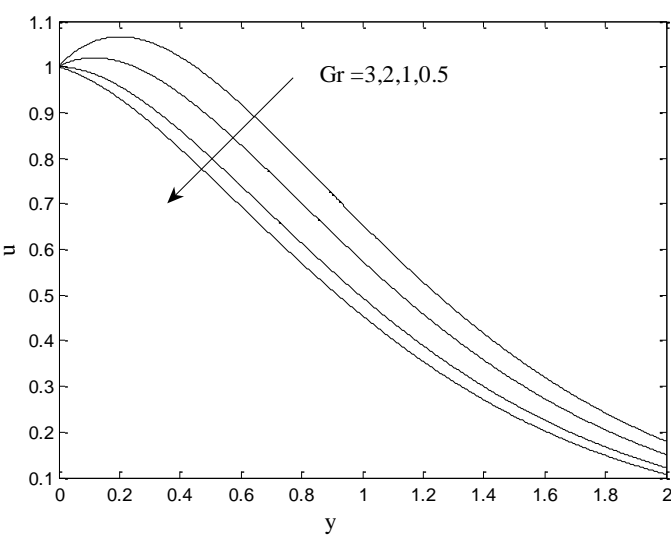

Fig. 4: Effect of Gr on velocity profile

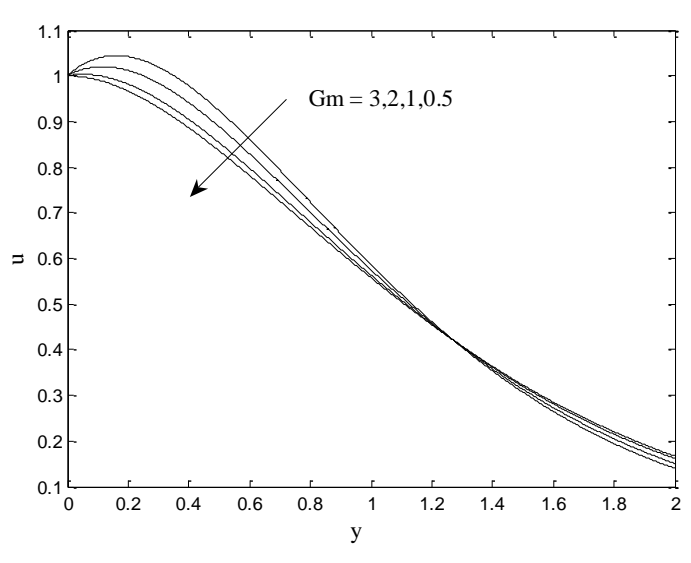

Fig. 5: Effect of Gm on velocity profile

\subsubsection{Effect of Schmidt number on velocity profile}

Fig. 6 shows the effect of Schmidt number $(\mathrm{Sc})$ on velocity profile. In this figure we have taken $\operatorname{Pr}=0.71$, $\mathrm{M}=0.5, \mathrm{Gr}=\mathrm{Gm}=2, K_{\mathrm{c}}=\phi=\mathrm{t}=1$. It is observed that for the heavier species, that is, with increasing Sc, the velocity of the fluid decreases. The values of Sc are chosen such that they represent Helium (Sc=0.3), water vapor $(\mathrm{Sc}=0.6)$, ammonia $(\mathrm{Sc}=0.78)$, carbon dioxide $(\mathrm{Sc}=0.94)$ and ethyl benzene $(\mathrm{Sc}=2.0)$. Schmidt number is the ratio of kinematic viscosity to molecular diffusivity. So, for heavier species $(\mathrm{Sc}>1)$, the kinematic viscosity dominates the molecular diffusivity as a result of which the velocity of the fluid decreases.

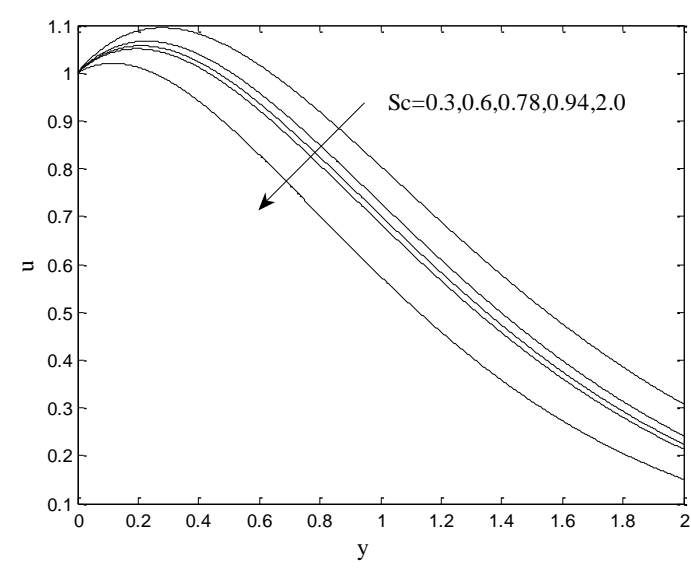

Fig. 6: Effect of Sc on velocity profile

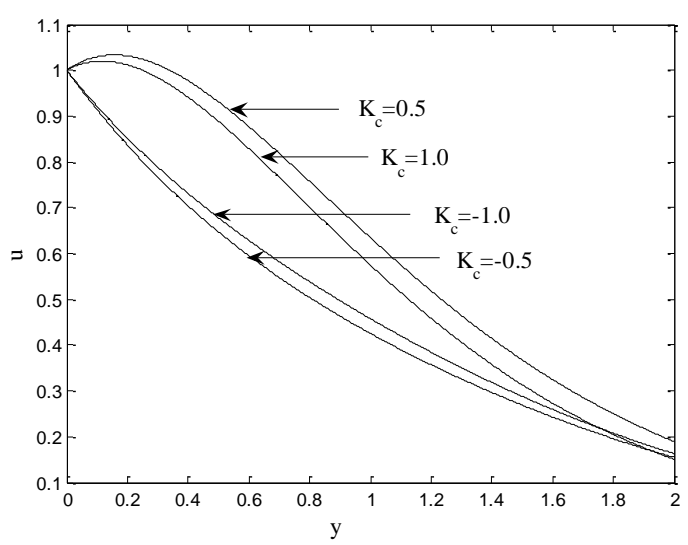

Fig. 7: Effect of $\mathrm{K}_{\mathrm{c}}$ on velocity profile

\subsubsection{Effect of chemical reaction parameter on velocity profile}

Fig. 7 shows the effect of chemical reaction parameter $\left(K_{\mathrm{c}}\right)$ on velocity profile. In this figure we have taken $\operatorname{Pr}=0.71, \mathrm{M}=0.5, \mathrm{Gr}=\mathrm{Gm}=2, \mathrm{Sc}=2, \phi=\mathrm{t}=1$. It is observed that in case of destructive reaction $\left(K_{\mathrm{c}}>0\right)$, the velocity of the flow field decreases with an increase in the chemical reaction parameter. But in case of generative reaction $\left(K_{\mathrm{c}}<0\right)$, the velocity of the flow field increases with a decrease in the chemical reaction parameter.

\subsubsection{Effect of heat source parameter on velocity profile}


Fig. 8 shows the effect of heat source parameter $(\phi)$ on the velocity profile. In this figure we have taken $\mathrm{Pr}=0.71, \mathrm{M}=0.5, \mathrm{Gr}=\mathrm{Gm}=2, \mathrm{Sc}=2, K_{\mathrm{c}}=\mathrm{t}=1$. It is interesting to note that increase in heat source parameter decreases the velocity of the flow. In presence of thermal sink (heat absorption) the velocity of the flow also reduces. This may happen due to the presence of chemical reaction parameter.

\subsubsection{Effect of time parameter on velocity profile}

Fig. 9 shows the effect of time parameter $(\mathrm{t})$ on the velocity field. In this figure we have taken $\operatorname{Pr}=0.71, \mathrm{M}=0.5$, $\mathrm{Gr}=\mathrm{Gm}=2, \mathrm{Sc}=2, K_{\mathrm{c}}=\phi=1$. It is marked that as time increases the velocity of the fluid also increases. It is also marked from the two upper curves of the time parameter graph that for less time the velocity of the fluid near the plate has a moderate rise and then falls slowly.

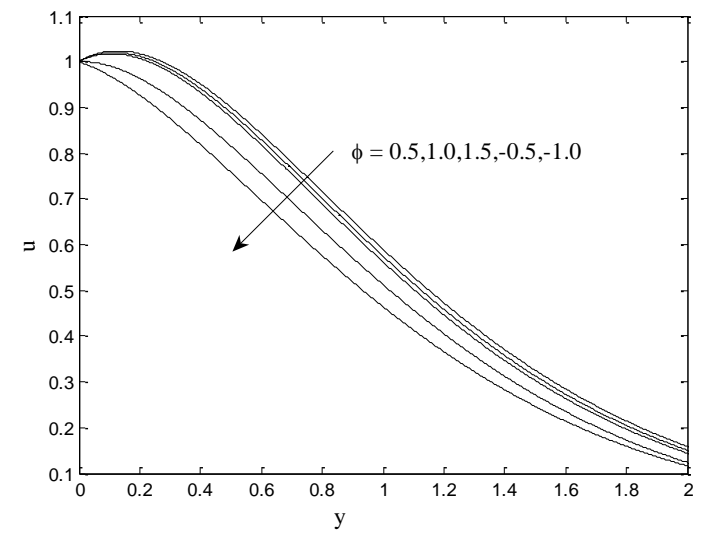

Fig. 8: Effect of $\phi$ on velocity profile

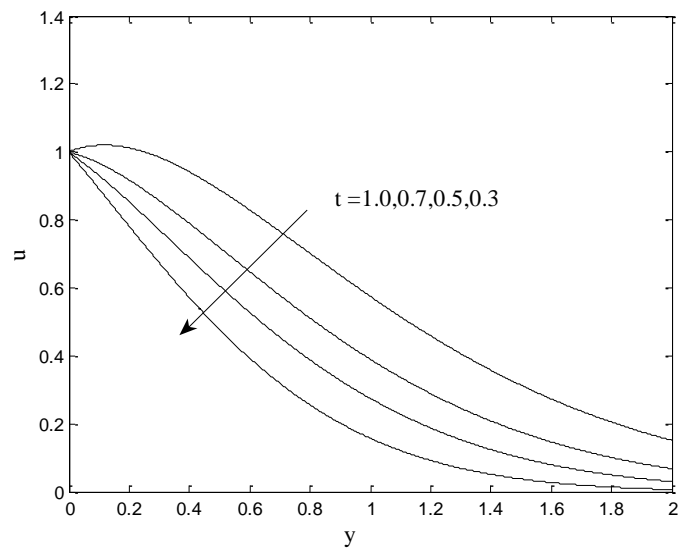

Fig. 9: Effect of t on velocity profile

\subsection{Effect of flow parameters on temperature profile}

Fig. 10 shows the effect of Prandtl number $(\operatorname{Pr})$ and heat source parameter $(\phi)$ on the temperature field. From the figure it is clear that as Pr increases, the temperature of the flow field decreases. For less viscous fluids (small value of Pr), the kinematic viscosity is dominated by the thermal diffusivity of the fluid. For highly viscous fluids (large value of Pr), the thermal diffusivity is dominated by the kinematic viscosity of the fluid. As a result of which a multilayer character exhibits in the temperature field. Again, from the two bottom curves of the graph it is observed that for highly viscous fluids the presence of heat source parameter diminishes the temperature of the fluid. But the reverse effect is observed in case of less viscous fluid.

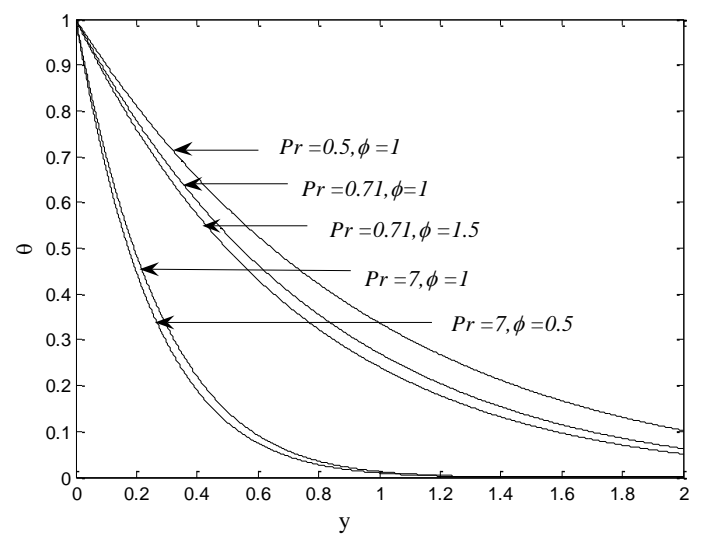

Fig. 10: Effect of Pr and $\phi$ on temperature profile

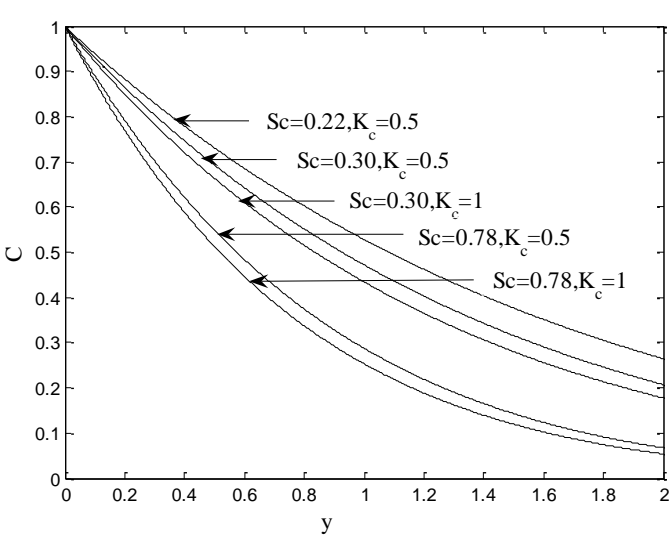

Fig. 11: Effect of Sc and $K_{\mathrm{c}}$ on concentration profile

\subsection{Effect of flow parameters on concentration profile}


Fig. 11 depicts the effect of Schmidt number $(\mathrm{Sc})$ and chemical reaction parameter $\left(K_{\mathrm{c}}\right)$ on concentration distribution. We know that Schmidt number characterizes the fluid flows in which there are simultaneous momentum and mass diffusion convection processes. It is observed that the increase in Schmidt number decreases the concentration distribution at all points of the flow domain. This shows that heavier diffusing species have a greater retarding effect on the concentration distribution of the flow field. It is also observed that an increase in chemical reaction parameter decreases the concentration distribution.

\subsection{Effect of flow parameters on skin friction}

Table 1 presents the values of skin friction for different flow parameters. It is the friction between the fluid and the surface of the solid moving through it. Skin friction characterizes the frictional drag at the solid surface. It is marked that the skin friction increases with an increase in $\mathrm{Pr}, \mathrm{M}, \mathrm{Gr}, K_{\mathrm{c}}$ and $\mathrm{t}$ whereas decreases with an increase in $\mathrm{Gm}$, Sc and $\phi$.

Table 1: The skin friction $(\tau)$

\begin{tabular}{|c|c|c|c|c|c|c|c|c|}
\hline $\mathrm{Pr}$ & $\mathrm{M}$ & $\mathrm{Gr}$ & $\mathrm{Gm}$ & $\mathrm{Sc}$ & $K_{\mathrm{c}}$ & $\phi$ & $\mathrm{t}$ & $\tau$ \\
\hline 0.5 & 0.5 & 0.5 & 0.5 & 0.6 & 0.5 & 0.5 & 0.5 & -1.7319 \\
\hline 0.71 & 0.5 & 0.5 & 0.5 & 0.6 & 0.5 & 0.5 & 0.5 & 0.3903 \\
\hline 0.5 & 1.0 & 0.5 & 0.5 & 0.6 & 0.5 & 0.5 & 0.5 & -1.2672 \\
\hline 0.5 & 0.5 & 1.0 & 0.5 & 0.6 & 0.5 & 0.5 & 0.5 & 0.3599 \\
\hline 0.5 & 0.5 & 0.5 & 1.0 & 0.6 & 0.5 & 0.5 & 0.5 & -4.5659 \\
\hline 0.5 & 0.5 & 0.5 & 0.5 & 0.78 & 0.5 & 0.5 & 0.5 & -4.6922 \\
\hline 0.5 & 0.5 & 0.5 & 0.5 & 0.6 & 1.0 & 0.5 & 0.5 & 1.7350 \\
\hline 0.5 & 0.5 & 0.5 & 0.5 & 0.6 & 0.5 & 1.5 & 0.5 & -3.9529 \\
\hline 0.5 & 0.5 & 0.5 & 0.5 & 0.6 & 0.5 & 0.5 & 1.0 & -1.6269 \\
\hline
\end{tabular}

\subsection{Effect of flow parameters on Nusselt number}

Table 2 presents the values of Nusselt number for different flow parameters. In heat transfer at the surface within the fluid, the Nusselt number $(\mathrm{Nu})$ is the ratio of convective to conductive heat transfer across the boundary. It is observed that the Nusselt number increases with an increase in $\operatorname{Pr}, \phi$ and $t$.

Table 2: The Nusselt number $(\mathrm{Nu})$

\begin{tabular}{|c|c|c|c|}
\hline $\operatorname{Pr}$ & $\phi$ & $\mathrm{t}$ & $\mathrm{Nu}$ \\
\hline 0.50 & 0.5 & 0.5 & 0.5491 \\
\hline 0.71 & 0.5 & 0.5 & 0.6543 \\
\hline 0.71 & 1.0 & 0.5 & 0.7109 \\
\hline 0.71 & 0.5 & 1.0 & 1.0053 \\
\hline 7.0 & 0.5 & 1.0 & 3.1566 \\
\hline 7.0 & 1.0 & 1.0 & 3.8936 \\
\hline
\end{tabular}

Table 3: The Sherwood number (Sh)

\begin{tabular}{|c|c|c|c|}
\hline $\mathrm{Sc}$ & $K_{\mathrm{c}}$ & $\mathrm{t}$ & $\mathrm{Sh}$ \\
\hline 0.3 & 0.5 & 0.5 & 0.4253 \\
\hline 0.6 & 0.5 & 0.5 & 0.6015 \\
\hline 0.6 & 1.5 & 0.5 & 0.7298 \\
\hline 0.6 & 0.5 & 1.0 & 0.9241 \\
\hline 2.0 & 0.5 & 0.5 & 1.0982 \\
\hline
\end{tabular}

\subsection{Effect of flow parameters on Sherwood number}

Table 3 presents the values of Sherwood number for different flow parameters. In mass transfer at the surface within the fluid, the Sherwood number(Sh) is the ratio of convective to diffusive mass transfer across the boundary. It is to note that all the entries of Sherwood number are positive. It is observed that the Sherwood number increases with an increase in $\mathrm{Sc}, K_{\mathrm{c}}$ and t.

\section{Conclusion}

A theoretical study on MHD flow past a vertical plate with variable temperature in the presence of heat source and chemical reaction has been studied. The concluding remarks are as follows: 
- An increase in both Prandtl number and magnetic parameter decreases the velocity of the flow field.

- Both thermal Grashof number and solutal Grashof number have an accelerating effect on the velocity profile.

- In case of heavier species, due to the dominance behavior of kinematic viscosity over molecular diffusivity, the velocity of the fluid decreases.

- In case of generative reaction, as the chemical reaction parameter decreases, the velocity of the flow also decreases.

- An increase in Prandtl number decreases the temperature of the flow field.

- The heavier diffusing species have a greater retarding effect on the concentration distribution of the flow field.

\section{References}

Al-Odat, M. Q. and Al-Azab, T. A. (2007): Influence of chemical reaction on transient MHD free convection over a moving vertical plate, Emirates Journal for Engineering. Research, Vol.12, No.3, pp.15-21.

Chamkha, A. J.(2004): Unsteady MHD convective heat and mass transfer past a semi-infinite vertical permeable moving plate with heat absorption, International Journal of Engineering Science, Vol. 42, pp.217-230.

http://dx.doi.org/10.1016/S0020-7225(03)00285-4

Cussler, E.L.(1988): Diffusion Mass Transfer in Fluid Systems, Cambridge University Press, London.

Das S.S., Mohanty M., Panda J.P. and Sahoo S.K.(2008): Hydromagnetic three dimensional Couette flow and heat transfer, Journal of Naval Architecture and Marine Engineering, Vol. 5, pp.1-10. http://dx.doi.org/10.3329/jname.v5i1.1784

Kandasamy, R., Periasamy, K. and Sivagnana, Pravu K.K (2005): Chemical reaction, heat and mass transfer on MHD flow over a vertical stretching surface with heat source and thermal stratification effects, International Journal of Heat Mass Transfer, Vol.48, pp. 4557-4561. http://dx.doi.org/10.1016/j.ijheatmasstransfer.2005.05.006

Kar, M., Sahoo, S.N., Rath, P.K. and Dash, G.C.(2014): Heat and mass transfer effects on a dissipative and radiative viscoelastic MHD flow over a stretching porous sheet. Arabian Journal of Science and Engineering, Vol.39, No.5, pp.3393-3401. http://dx.doi.org/10.1007/s13369-014-0991-0

Mahapatra, N., Dash, G.C., Panda, S. and Acharya, M.(2010): Effects of chemical reaction on free convection flow through a porous medium bounded by a vertical surface, Journal of Engineering Physics and Thermophysics, Vol.83, No.1, pp.130-140. http://dx.doi.org/10.1007/s10891-010-0327-1

Mahmoud, M.A.A.(2007): A note on variable viscosity and chemical reaction effects on mixed convection heat and mass transfer along a semi-infinite vertical plate, Mathematical Problems in Engineering, Vol. 2007, Article ID 41323. http://dx.doi.org/10.1155/2007/41323

Muthucumarswamy, R.(2002): Effects of chemical reaction on a moving isothermal vertical surface with suction, Acta Mechanica, Vol. 155, No . 1-2.pp. 65-70. http://dx.doi.org/10.1007/BF01170840n

Muthukumarswamy, R. and Janakiraman, B.(2006): MHD and radiation effects on moving isothermal vertical plate with variable mass diffusion, Theoretical and Applied Mechanics, Vol. 33, No. 1, pp.17-29. http://dx.doi.org/10.2298/TAM0601017M

Muthukumarswamy, R. Sathappan, K.E. and Natarajan, R. (2008): Mass transfer effects on exponentially accelerated isothermal vertical plate, International Journal of Applied Mathematics and Mechanics, Vol. 4, No. 6, pp.19-25.

Prasad, V.R., Reddyn, N.B. and Muthukumarswamy, R. (2007): Radiation and mass transfer effects on twodimensional flow past an impulsively started infinite vertical plate, International Journal of Thermal Sciences., Vol. 46, No. 12, pp.1251-1258. http://dx.doi.org/10.1016/j.ijthermalsci.2007.01.004

Rajput, U.S. and Kumar, S. (2011): MHD flow past an impulsively started vertical plate with variable temperature and mass diffusion, Applied Mathematical Sciences, Vol. 5, No. 3, pp.149-157. http://dx.doi.org/mhikari.com/ams/ams/-2011/ams-1-4-2011/kumarAMS1-4-2011

Raptis, A. and Perdikis, C.(2006): Viscous flow over a non-linearly stretching sheet in the presence of a chemical reaction and magnetic field, International Journal of Non-Linear Mechanics, Vol. 41, pp.527-529.

http://dx.doi.org/10.1016/j.ijnonlinmec.2005.12.003

Seth, G.S. and Ansari, S.(2010): MHD natural convection flow past an impulsively moving vertical plate with ramped wall temperature in the presence of thermal diffusion with heat absorption, International Journal of Applied Mechanics and Engineering, Vol.15, No.1, pp.199-215. 